\title{
Monoclonal antibodies to inner ear antigens: I. Antigens expressed by supporting cells of the guinea pig cochlea
}

\author{
Gary Zajic, Thankam S. Nair, Martin Ptok, Carter Van Waes, Richard A. Altschuler, \\ Jochen Schacht and Thomas E. Carey \\ Kresge Hearing Research Institute, The University of Michigan, Ann Arbor, Michigan, U.S.A.
}

(Received 16 April 1990; accepted 17 September 1990)

\begin{abstract}
Murine monoclonal antibodies against guinea pig cochlear epithelium were generated with the goal of identifying cochlea-specific antigens and elucidating their function. To compensate for the limited amount of cochlear tissue, intrasplenic immunization was used. Hybridoma supernatants were screened by ELISA for antibody production and for binding to homogenates from cochlea, liver, lung, kidney and brain. Hybrids producing antibody to cochlea were subcloned and tested immunocytochemically against frozen sections and surface preparations of paraformaldehyde-fixed cochlear tissue. KHRI-1, a low titer IgM antibody stained only Hensen cells. KHRI-2, also an IgM antibody, stained tectorial membrane, cells of the spiral limbus, cells bordering the space of Nuel, Hensen cells and the root cells of the spiral prominence. KHRI-3, an IgG1 antibody, stained the phalangeal processes of outer pillar cells and the apical portion of phalangeal processes of Deiters' cells in a distinctive wine goblet pattern on surface preparations. KHRI-3 antibody also reacted with peripheral nerves and pia mater of brain in unfixed frozen sections but the antigenic site was not stable to fixation in contrast to the epitope detected in the cochlea. In Western blots of detergent extracts from cochlea KHRI-3 stained a broad tissue-specific band of $M_{r} 70-75 \mathrm{kDa}$; a narrower band of $\mathrm{M}_{\mathrm{r}}$ 68-70 kDa was identified by KHRI-3 in extracts of tongue and brain. KHRI-1 and KHRI-2 did not detect any proteins in Western blots. The monoclonal antibodies KHRI-1, -2 , and -3 which define epitopes expressed by discrete populations of supporting cells in the inner ear should be useful in characterizing the nature and function of cellular structures in the cochlea.
\end{abstract}

Cochlea; Monoclonal antibodies; Supporting cells

\section{Introduction}

Specialized plasma membrane components enable cells to maintain intracellular homeostasis and respond to environmental signals such as hormones, neurotransmitters or mechanical stimuli. Little is known about the function of supporting cells and structures in the cochlea, such as the spiral limbus components (interdental and interstitial cells) and Huschke's teeth or supporting cells within or adjacent to the organ of Corti (Hensen, Claudius and Boettcher's cells).

Correspondence to: Thomas E. Carey, Kresge Hearing Research Institute, The University of Michigan, 1301 E. Ann Street, Ann Arbor, MI 48109-0506, U.S.A. FAX: 313 764-0014.
Antibodies are powerful reagents to identify, characterize and elucidate the nature and function of cell-specific molecules. For example, the discovery and characterization of the integrin super-family of extracellular matrix receptors essential to development, differentiation and function of numerous tissues evolved from analysis of the antigens detected by antibodies raised to activated lymphocytes and tumor cells (Hemler et al., 1983; Sonnenberg et al., 1988). Antibodies to cochlear tissue might recognize structures unique to the inner ear, distinguish between morphologically identical subsets of cells or reveal molecular similarities between different cell types. Furthermore, physiological investigations of the effects of antibody reactions with specific cells would contribute to our knowledge of their function in the molecular mechanisms of auditory processing. 
A major difficulty in raising and screening monoclonal antibodies to the organ of Corti is the small amount of protein available from this tissue. We describe here an immunization procedure and screening assay suitable for the development of specific antibodies to cochlear tissue and report the tissue distribution and preliminary characterization of the cochlear antigens identified by the first generation of antibodies.

\section{Materials and Methods}

\section{Isolated hair cells}

Isolated hair cells were prepared from pigmented guinea pigs (Murphy's Breeding Lab, Plainfield, IN) essentially according to procedures described previously (Zajic and Schacht, 1987). Bullae were opened immediately after euthanasia and the cochleae were placed in Hanks' Balanced Salt Solution (HBSS). A segment of the organ of Corti containing outer hair cells and adjacent supporting cells was dissected free from the basilar membrane. This tissue was transferred to a fresh droplet of HBSS where cells were separated by gentle aspiration with a micropipette. After the cells were allowed to settle, the Hensen cells which remained in intact rows were removed and discarded. The remaining cell suspension consisted primarily of hair cells, phalangeal processes of Deiters' cells, pillar cells, some Hensen cells and pieces of tectorial membrane. Tissue from 10 cochleae (approximately 2000 outer hair cells and some contaminating supporting cells) was used for each immunization.

\section{Immunization}

The intrasplenic immunization method described by Spitz (1986) was adapted. Eight to 10-week old pathogen-free BALB/c mice were anesthetized with sodium pentabarbitol, the spleen was exteriorized and approximately $90 \mu 1$ of tissue homogenate was slowly injected through a 26 gauge needle fitted to a $100 \mu \mathrm{l}$ Hamilton glass syringe. The spleen was returned to the peritoneal cavity, the peritoneum and muscle layer were sutured, and the skin incision was closed. In some experiments, the animals were also given three intravenous immunizations via the tail vein at two week intervals prior to intrasplenic immunization.

\section{Hybridomas}

Fusion was carried out by a modification of Köhler and Milstein (1975) as previously described (Kimmel and Carey, 1986). Three days following the intrasplenic immunization the spleen was removed, a cell suspension prepared in serum-free Iscove's medium (Gibco, Grand Island, NY) and centrifuged at $250 \times \mathrm{g}$ for $10 \mathrm{~min}$. The pellet was resuspended in cold $0.83 \% \mathrm{NH}_{4} \mathrm{Cl}$ to lyse red blood cells, and after washing with medium the lymphoid cells were counted and transferred to a round-bottom tube.

Myeloma cells (SP2/0) in logarithmic growth were washed, counted, resuspended in serum-free medium and added to the spleen cells in a $1: 3$ ratio. The mixture was centrifuged for $5 \mathrm{~min}$ at $500 \times \mathrm{g}$ at room temperature, the medium was aspirated and the cells were fused in $33 \%$ polyethylene glycol (PEG 1000, Koch Light Ltd., U.K.). After centrifugation for $6 \mathrm{~min}$ at $250 \times \mathrm{g}$, the PEG was slowly diluted with medium and the cells were again centrifuged for $7 \mathrm{~min}$ at $250 \times \mathrm{g}$. The supernatant was replaced with fresh medium containing $20 \%$ fetal calf serum, the cells were gently resuspended and transferred to two $100 \mathrm{~mm}$ Petri dishes. After $24 \mathrm{~h}$ incubation at $37^{\circ} \mathrm{C}$ in a humidified $5 \% \mathrm{CO}_{2}$ atmosphere, the volume of medium was doubled and after another $24 \mathrm{~h}$ the cells were transferred to medium containing $100 \mathrm{mM}$ hypoxanthine, $0.4 \mathrm{mM}$ aminopterin, $16 \mathrm{mM}$ thymidine (HAT medium, Sigma, St. Louis, MO.), and distributed to 96-well plastic culture plates (Falcon, Becton Dickenson, Lincoln Park, NJ).

\section{Screening}

Antibody-secreting clones were selected for reactivity against cochlear antigens in a microassay modified after Liebert et al. (1985). Cells dissected from organ of Corti preparations, as described above, were frozen, thawed, and sonicated twice at $20 \mathrm{kHz}$ for $2 \mathrm{~s}$ at room temperature (Cole Palmer Ultrasonicator, Chicago, IL). The protein content was determined by a micro-gold protein assay, modified for ELISA, with a linear range from 20 to $180 \mathrm{ng}$ protein. The organs of Corti from six cochleae typically yielded $100 \mu \mathrm{g}$ of protein. The homogenates were adjusted to $1 \mu \mathrm{g}$ protein $/ \mathrm{ml}, 50$ $\mu 1$ were dispensed into each well of 96-well mirotiter plates pre-coated with $1 \mathrm{mg}$ /well of Cell-Tak 
(Bio-Polymers, Farmington, CT) and incubated at $4^{\circ} \mathrm{C}$ overnight. The plates were washed and residual sites blocked with $1 \%$ normal horse serum in phosphate-buffered saline (PBS), followed by three PBS washes. Hybridoma supernatants $(100 \mu 1)$ were added and incubated for $1 \mathrm{~h}$ at room temperature. The plates were washed with PBS, $50 \mu 1$ of 1:1000 dilution of biotinylated horse anti-mouse IgG (Vector Labs, Burlingame, CA) containing 1\% normal horse serum were added to each well and incubated for $30 \mathrm{~min}$. Plates were washed with PBS, and incubated for $15 \mathrm{~min}$ with $50 \mu \mathrm{l} /$ well of avidin-biotin complex conjugated to alkaline phosphatase (ABC reagent, Vector Labs) in PBS containing $0.1 \%$ Tween 20 . After 5 washes with PBS, $100 \mu 1$ of $2 \mathrm{mg} / \mathrm{ml}$ p-nitrophenylphosphate in $100 \mathrm{mM} \mathrm{NaHCO}$ and $10 \mathrm{mM} \mathrm{MgCl}$, pH 9.5, were added and the absorbance at $415 \mathrm{~nm}$ was determined after $30 \mathrm{~min}$.

To determine reactivity with non-cochlear tissues, brain, spleen, kidney, and other tissues were homogenized at a concentration of $1 \mathrm{~g}$ tissue/10 $\mathrm{ml}$ of buffer (Polytron, Brinkmann Instruments, Lucerne, Switzerland) (0.01 M sodium HEPES, $0.25 \mathrm{M}$ sucrose, $\mathrm{pH}$ 7.4), containing the protease inhibitors phenylmethylsulfonyl fluoride (PMSF, $1 \mathrm{mM})$, leupeptin $(1 \mu \mathrm{g} / \mathrm{ml})$, antipain $(2 \mu \mathrm{g} / \mathrm{ml})$, benzamidine $(10 \mu \mathrm{g} / \mathrm{ml})$, aprotinin $(10 \mathrm{ku} / \mathrm{ml})$, chymostatin $(1 \mu \mathrm{g} / \mathrm{ml})$ and pepstatin $(1 \mu \mathrm{g} / \mathrm{ml})$. The homogenate was filtered through gauze and clarified by centrifugation $(15 \mathrm{~min}, 8000 \times \mathrm{g})$. A crude membranc fraction was precipitated by addition of $\mathrm{CaCl}_{2}$ to a final concentration of $1 \mathrm{mM}$. After $30 \mathrm{~min}$ on ice the microsomes were pelleted by centrifugation $(15 \mathrm{~min}, 20,000 \times \mathrm{g})$ and resuspended in $0.01 \mathrm{M}$ sodium HEPES, $0.14 \mathrm{M} \mathrm{KCl}$, pH 7.4. This fraction was adjusted to a protein content of $10 \mu \mathrm{g} / \mathrm{ml}$ in $50 \mathrm{mM} \mathrm{NaCO}, \mathrm{pH} \mathrm{9.6,}$ and distributed (100 $\mu \mathrm{l} /$ well) to 96 -well plates which were wrapped in parafilm and stored at $-20^{\circ} \mathrm{C}$ until used for ELISA.

Hybridoma supernatants were tested for antibody content by ELISA. Plastic 96-well plates were coated with affinity-purified horse anti-mouse IgG light and heavy chain (Vector Labs, Burlingame, $\mathrm{CA}$ ) in $50 \mathrm{mM} \mathrm{NaHCO}$ buffer, $\mathrm{pH} \mathrm{9.6,} \mathrm{at}$ a concentration of $0.2 \mu \mathrm{g} / 100 \mu \mathrm{l} /$ well and incubated at $37^{\circ} \mathrm{C}$ overnight. Uncoated sites were blocked with horse serum, hybridoma super- natants were added and screened using the avidin-biotin alkaline phosphatase ELISA as described above.

\section{Immunocytochemical assays}

Binding of antibody-containing supernatants was examined in cryostat sections and surface preparations of the guniea pig cochlea either unfixed or fixed by perfusion of $2 \%$ paraformaldehyde in HBSS through the round window. For cryostat sectioning the otic capsule was removed, $25 \%$ sucrose in HBSS used as a cryoprotectant and $10 \mu \mathrm{m}$ sections cut. For surface preparations freefloating whole turns of the cochlear spiral were used. Immunofluorescent and immunoperoxidase procedures were carried out as described previously (Fex and Altschuler, 1985) using the Vectastain reagents. Control sections were stained using an irrelevant $\operatorname{IgM}$ or $\operatorname{IgG}_{1}$ monoclonal antibody and the appropriate second antibody or second antibody alone. In some experiments with KHRI2, KHRI-3 and the control antibodies the images were recorded on videotape using a SIT camera at the same gain and KV settings. The images from cross sections of the cochlea were also analyzed using a Quantex QX7 image analysis system. A square area encompassing the entire cross section was averaged for fluorescent intensity as well as the region of the organ of Corti and a traced outline of the cochlear tissues. Other tissues were removed immediately after euthanasia, imbedded in Tissuc Tek medium and frozen in liquid nitrogen. Six to eight $\mu \mathrm{m}$ sections were fixed in acetone, incubated with hybridoma supernatants, washed, and stained by the immunoperoxidase method using the Vectastain avidin biotin complex kit (Vector Labs, Burlingame, CA) as described (Kimmel and Carey, 1986)

\section{Immunoglobulin (Ig) class determination}

Hybridoma supernatants were tested for Ig class with the Hyclone isotyping kit (Hyclone, Logan, UT) following the ELISA protocol provided by the manufacturer. In brief, 96-well plates precoated with goat anti-mouse Ig were serially incubated for $1 \mathrm{~h}$ with a $1: 1$ dilution of the hybridoma supernatant (in $0.05 \%$ Tween 20 in PBS), murine Ig class-specific rabbit antisera (IgA, IgM, $\operatorname{IgG}_{1}, \mathrm{IgG}_{2 \mathrm{a}}, \mathrm{IgG}_{2 \mathrm{~b}}, \mathrm{IgG}_{3}, 100 \mu \mathrm{l} /$ well), and goat 
anti-rabbit $\mathrm{IgG}$-peroxidase conjugate $(1: 4000 \mathrm{di}$ lution). Between incubations the plates were washed and at the end of the assay binding was visualized using the $o$-phenylenediamine color reaction. Absorbance was read at $490 \mathrm{~nm}$.

\section{Gel electrophoresis and immunoblotting}

Sodium dodecylsulfate-polyacrylamide gel electrophoresis (SDS-PAGE) was performed after
Laemmli (1970). Unfixed organ of Corti from six cochleae (per lane) were stripped from the modiolus and treated with 2 volumes of lysis buffer (1\% NP-40 in PBS containing the protease inhibitors as described above) at $4^{\circ} \mathrm{C}$ for $30 \mathrm{~min}$, followed by centrifugation $(11,000 \times \mathrm{g}, 5 \mathrm{~min})$. Tissue extracts of tongue and brain were prepared by dispersing with a Polytron (Brinkman Instruments, Lucerne, Switzerland) in $15 \mathrm{mM}$ Tris-HCl, $2 \mathrm{mM} \mathrm{CaCl}_{2}, 1 \mathrm{mM}$ PMSF, pH 8, filtered through

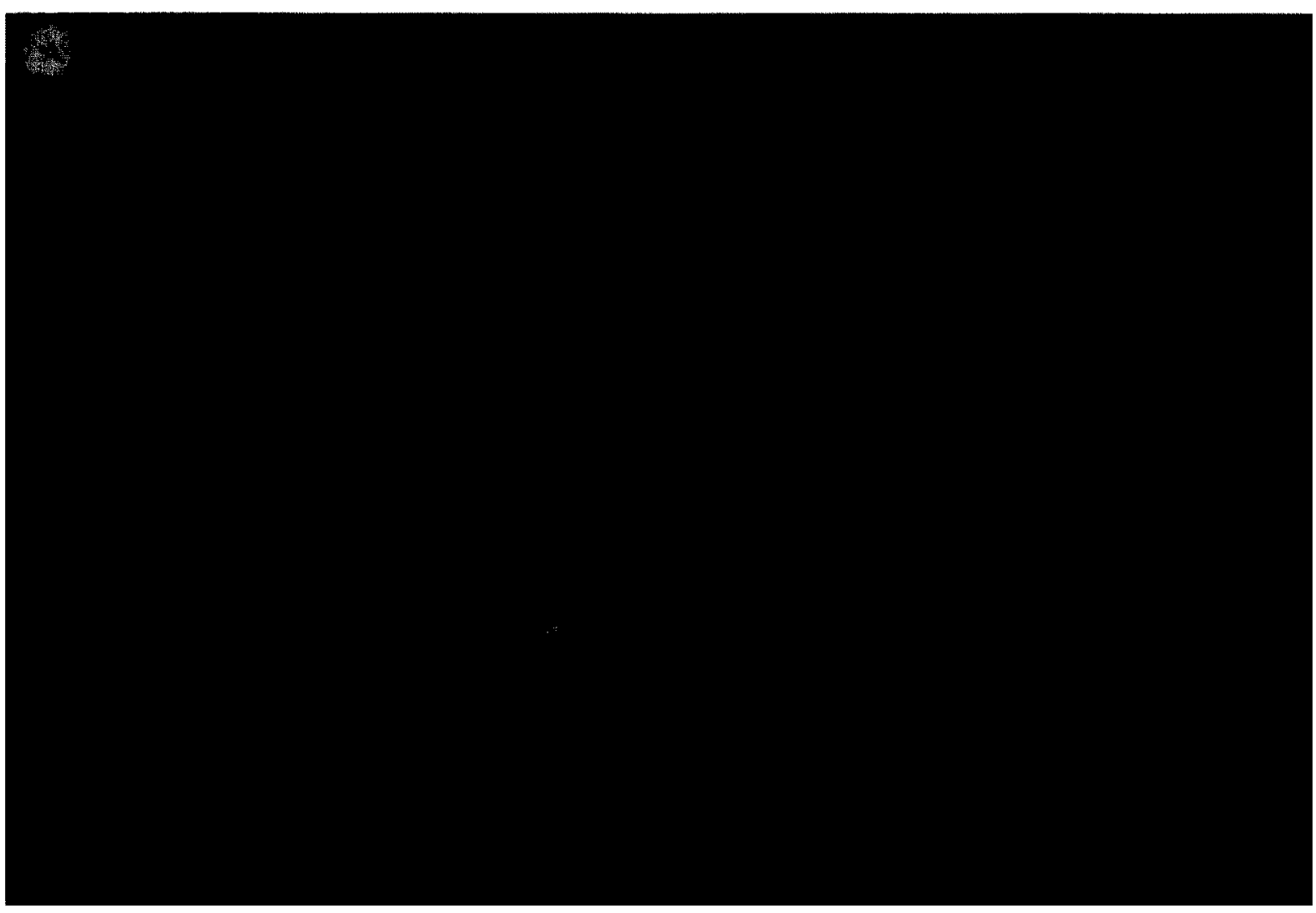

Fig. 1. Immunofluorescence staining of mid-modiolar sections of paraldehyde fixed guinea pig cochlea containing the organ of Curti. (A). KHRI-1 MAb stains only Hensen cells (HC). Other fluorescent structures were apparent only in long exposures and this could be attributed to autofluorescence of nuclei as well as low intensity staining of some other structures (see text). (B). KHRI-2 stains the tectorial membrane (TM), cells of the spiral limbus (SL), pillar cells (PC), Hensen cells (HC) and the root cells of the spiral prominence (RC). (C). KHRI-3 strongly stains the supporting cells bordering the tunnel of Corti (arrows). Other supporting cells in the organ of Corti are stained to a lesser extent. No staining of the sensory cells (HC) is present. Staining of the epithelial surface medial and lateral to the organ of Corti was noted. (D). KHRI-3 staining of the organ of Corti photographed through the SIT camera and recorded at the same settings as the control section shown in E. Although there was some background fluorescence in the control tissues, the staining by KHRI-3 was much greater than the control. When the average radiance (as determined with the Quantex image analysis system as described in the text) of the entire section stained by KHRI-3 (Fig. 1D) was compared to that of the control (Fig. 1E.) the values were 8 and 2 respectively and when the radiance was measured only over an outline of the tissues, the values were 39 for KIIRI-3 and only 7 for the control. (E). Organ of Corti cross section stained only with the anti-IgG second antibody used to detect KHRI-3 staining. 
gauze, pelleted by centrifugation $(11,000 \times \mathrm{g}, 15$ $\min$ ) and lysed as described above.

The tissue lysate supernatants were mixed with loading buffer (Tris-Cl, pH 6.8, 2\% SDS, 10\% glycerol, $0.005 \%$ bromphenol blue) to a final concentration of $100-150 \mu \mathrm{g}$ protein/sample/lane and subjected to SDS-PAGE on a $3 \%$ stacking and $7 \%$ separating gel. The separated proteins were transferred onto nitrocellulose paper (Towbin et al., 1979) which was cut into strips and blocked overnight in $50 \mathrm{mM}$ Tris- $\mathrm{HCl}, \mathrm{pH} 8.0$, containing $5 \%$ non-fat dry milk, $2 \mathrm{mM} \mathrm{CaCl} 2$ and $0.05 \%$ Tween 20. The nitrocellulose strips were then incubated for $2 \mathrm{~h}$ at room temperature with primary antibodies KHRI-1, -2 and -3 (1:10 dilution), antikeratin 8.13 (Sigma, St. Louis, MO; 1:100 dilution) as a positive control and $\mathrm{Sp} 2 / 0$ supernatant (1:10 dilution) as a negative control. After three 15-min washes in blocking solution, the strips were incubated at room temperature for $2 \mathrm{~h}$ in the second antibody, rat anti-mouse IgG (heavy and light chain-specific, Accurate Chemical and Scientific Corp., Westbury, NY) at a dilution of $1: 100$. After one brief wash in blocking solution and two 5 min washes in PBS ( $\mathrm{pH} \mathrm{7.6),} \mathrm{the} \mathrm{strips} \mathrm{were}$ developed in 4-chloro-1-naphthol $(0.5 \mathrm{mg} / \mathrm{ml})$ in methanol-PBS $(1: 5)$ containing $0.05 \% \quad \mathrm{H}_{2} \mathrm{O}_{2}$. When the positive control became clearly visible, the color development was stopped by washing the strips in water. Pre-stained standards (Amersham, Arlington Heights, IL) were used as molecular weight markers.

\section{Results}

Twenty eight hybridoma supernatants resulting from the first intrasplenic immunization tested positive for antibody binding against homogenates from the organ of Corti in ELISA screenings. Thirteen of the twenty-eight clones continued to

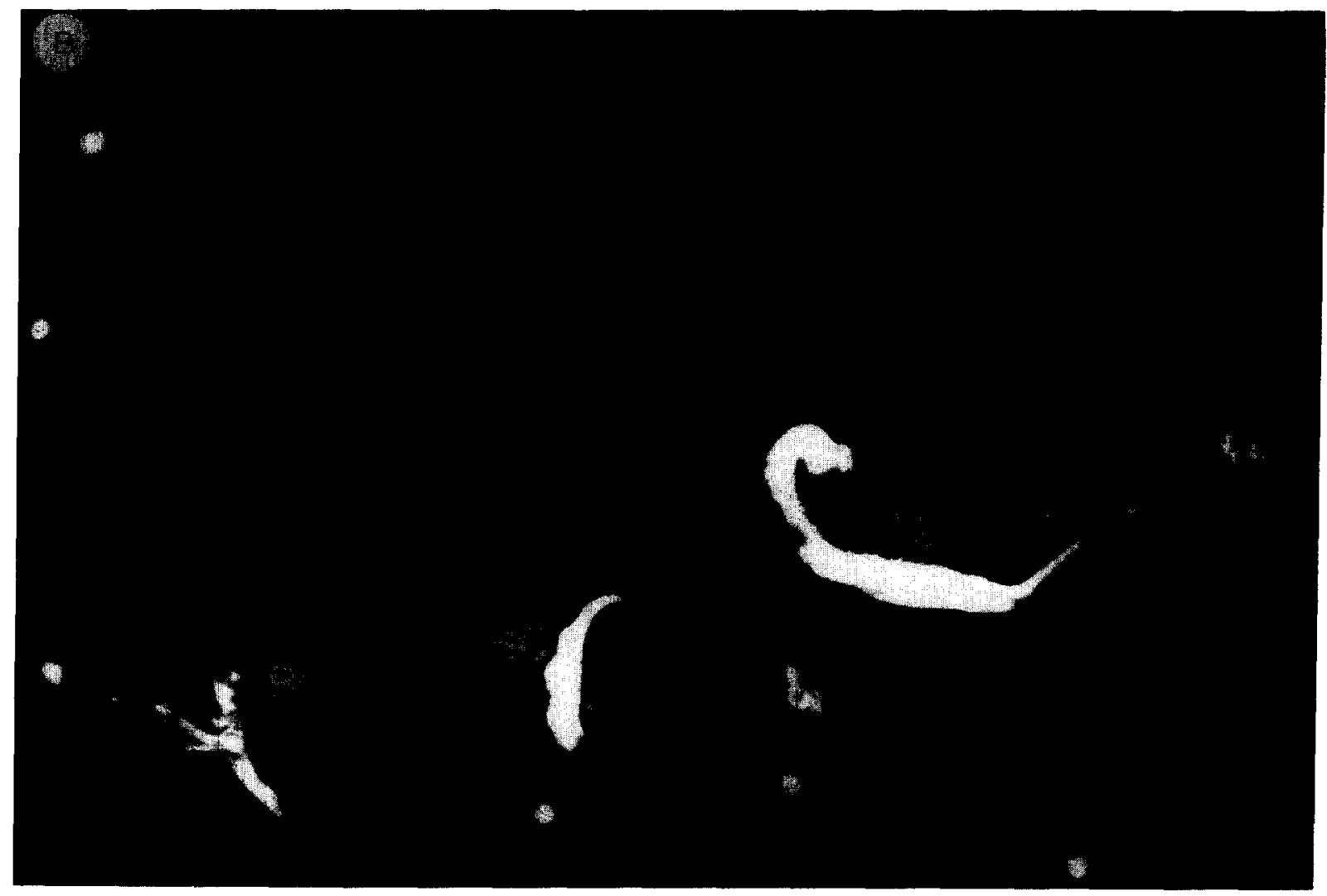

Fig. 1 (continued). 
proliferate, and five clones with relatively strong antibody binding activity were subcloned. Three of these continued to secrete antibody, and two with the strongest positive reactions against organ of Corti homogenates were selected for further study. Both antibodies, KHRI-1 and KHRI-2, were of the IgM class.

The second fusion prepared after sequential intravenous and intrasplenic immunizations yielded 53 antibody-producing clones of which six proliferated and one showed significant binding to the organ of Corti homogenate. This clone was subcloned twice and the IgG1 antibody produced (KHRI-3) was selected for further study.

\section{Antibody binding in organ of Corti}

The monoclonal antibodies were tested on midmodiolar sections of cochlea to determine localization within the organ of Corti. KHRI-1 stained
Hensen cells selectively as shown in Fig. 1a, but this staining was relatively weak. As a result nonspecific fluorescence of nuclei in the limbus, organ of Corti and basilar membrane as well as poorly stained regions in the lateral wall adjacent to the stria vascularis and the medial portion of the organ of Corti are visible. KHRI-2 labeled Hensen cells, pillar cells and the tectorial membrane (Fig. 1b) including the limbal portion of the tectorial membrane over the surface of the spiral limbus. In addition, staining of Huschke's teeth and interdental cells in this region, as well as the 'root cells' or external sulcus cells of the spiral prominence were stained by KHRI-2. In some experiments the surfaces of the inner sulcus cells were also stained. Staining of cochlear structures outside the organ of Corti is noteworthy because neither spiral ligament nor stria vascularis were included in the antigen preparation used for immunization. 
KHRI-3 antibody immunostained most prominently the cells bordering the tunnel of Corti and to a lesser extent the supporting cells of the second and third row of outer hair cells (Fig. 1c and d). In cross-section, staining of the first row of Deiters' cells surrounding the outer hair cells seemed more prominent than in the second and third rows. There was no staining of sensory hair cells. An example of the KHRI-3 fluorescent staining of organ of Corti in cross section and the control section photographed through the SIT camera under the same gain and KV settings are shown in Fig. 1d and e.

Surface preparations stained with KHRI-3 confirmed the findings obtained on cross sections. Punctate labeling of the reticular lamina, framed the sensory cells in a characteristic pattern of fluorescent staining that surrounded the inner hair cells and gave the appearance of a stack of 'wineglasses' surrounding the outer sensory cells. The staining appeared to be localized to the phalangeal processes of the Deiter's cells and pillar cells as well as the reticular lamina of the inner pillar and border cells surrounding the inner hair cells (Fig. 2). This staining pattern was observed both with immunoperoxidase and immunofluorescence excluding the possibility that the observed surface staining was a result of a 'light piping' artifact from subsurface staining with the immunofluorescence technique (Egelman, 1981).

\section{Antibody reactivity with non-auditory structures}

The monoclonal antibodies were also tested against fixed and frozen sections of guinea pig brain, eye, intestine, kidney, lip, liver, lung, muscle, spinal cord and tongue. No antibody staining was detected in any fixed non-cochlear tissues. This is in sharp contrast to the cochlea where all the immunohistology was performed on fixed tissues. We did detect some binding in frozen sections of

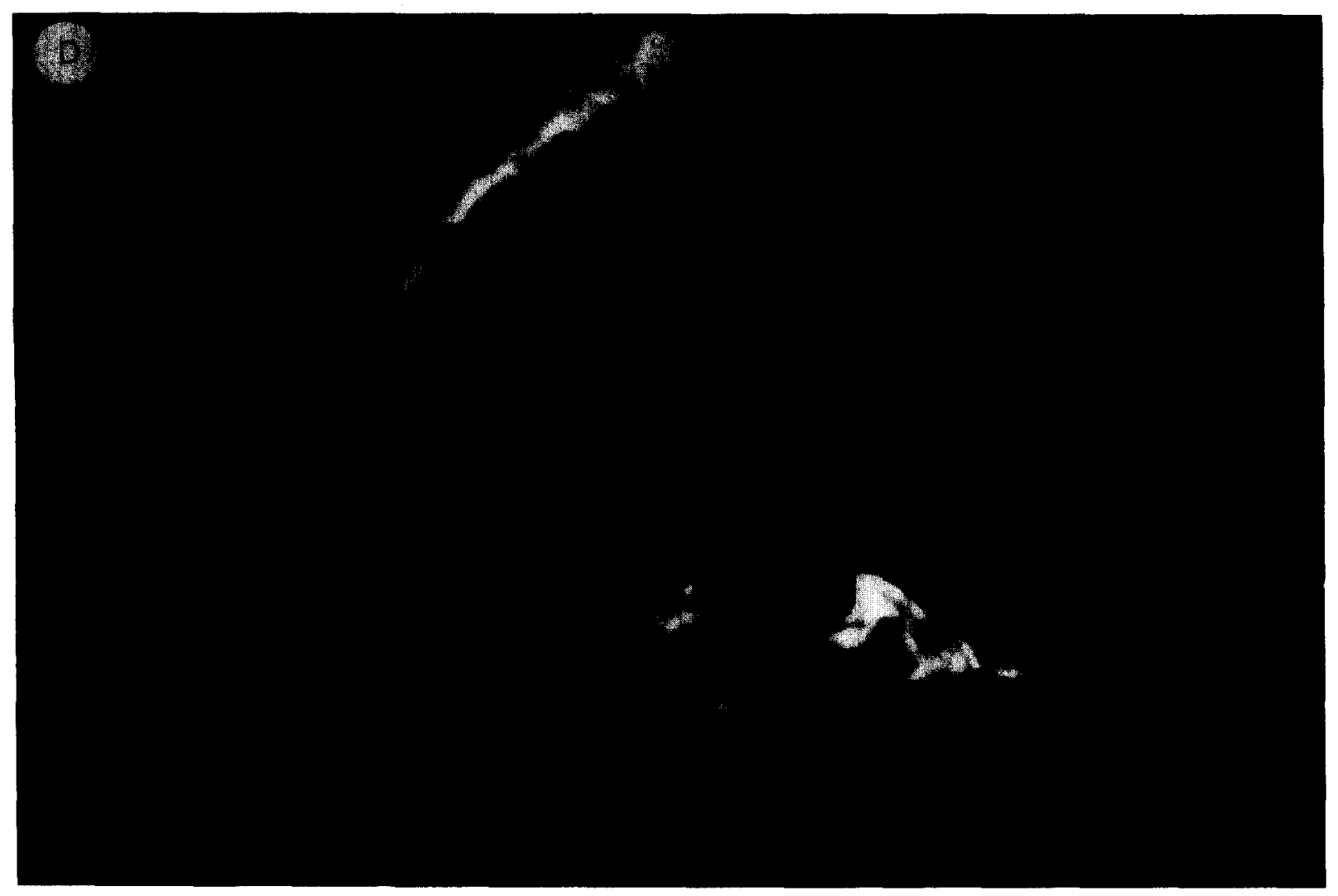

Fig. 1 (continued). 
unfixed peripheral tissues which suggests that the molecules that carry the reactive epitopes in the peripheral tissue are different than those in the auditory system since the former are apparently denatured by fixation. On frozen sections KHRI-1 was negative on all tissues. KHRI-2 stained basal epithelial cells of tongue and lip (Fig. 3a) and KHRI-3 strongly stained only peripheral nerve fibers (Fig. 3b) in muscle, tongue, lip, intestine, and eye. The optic nerve was also stained by KHRI-3 but much less intensely than the peripheral nerve fibers in the sclera of the optic globe (not shown). Brain and spinal cord, except for the pia mater of brain, were not stained.

\section{Western blotting}

Each of the antibodies was tested for the ability to detect its epitope on Western blots of detergent-extracted and SDS-PAGE-separated proteins from cochlea, brain and tongue. Only KHRI-3 identified proteins on the blots (Fig. 4). In cochlea, a prominent broad band of $70-75 \mathrm{kDa}$ and two minor bands of 64 and $78 \mathrm{kDa}$ were stained whereas in tongue and brain extracts a band of 68-70 kDa was observed.

\section{Discussion}

The monoclonal antibodies characterized in this report provide new tools for elucidating unique molecular components of supporting cells that may play a functional role in inner ear homeostasis and auditory processing. The specificity of these antibodies for the supporting elements is intriguing. The fact that the injected cochlear homogenate did not give rise to antibodies against the sensory cells could suggest that supporting cells possess stronger cross-species antigenicity

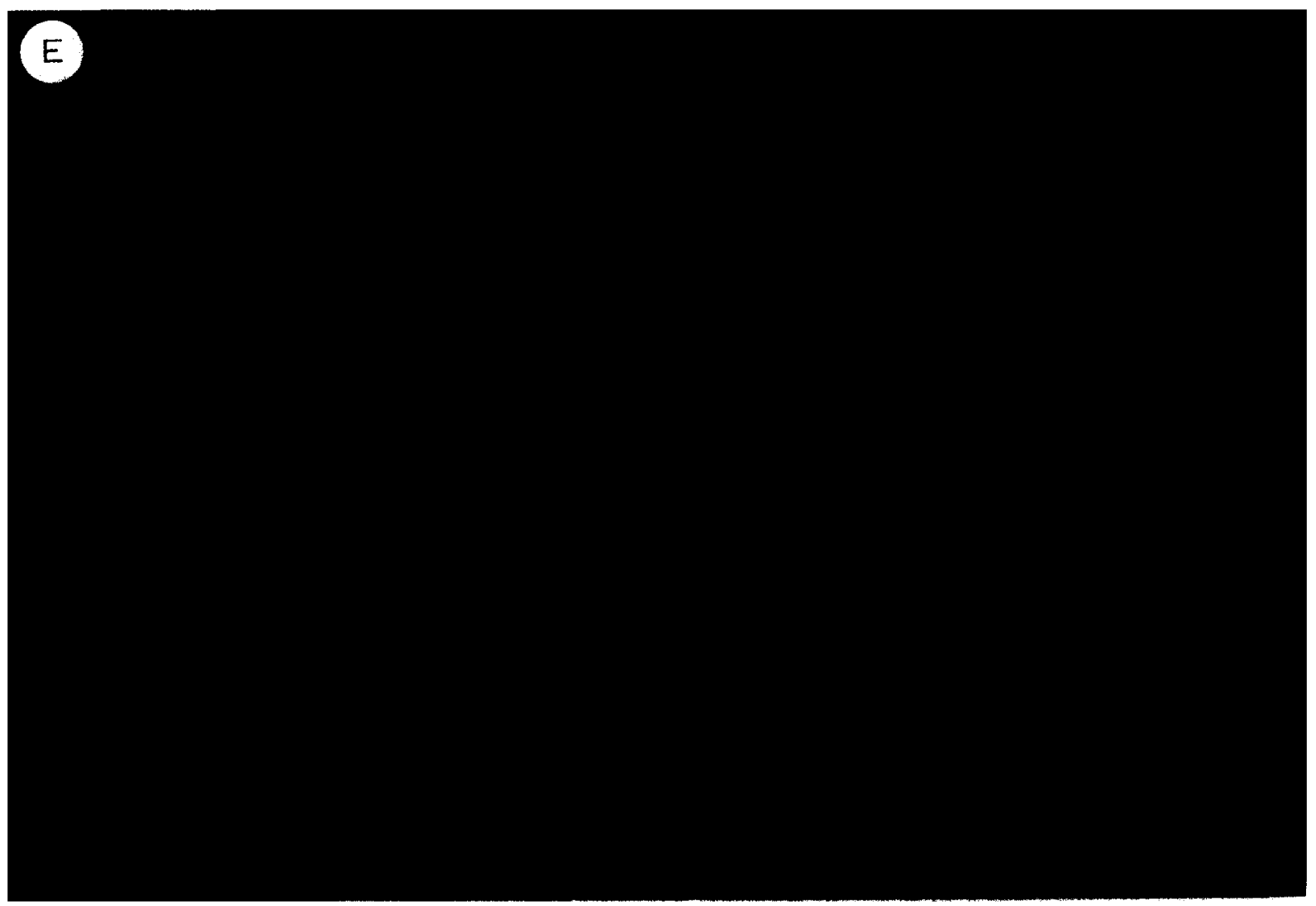

Fig. 1 (continued). 


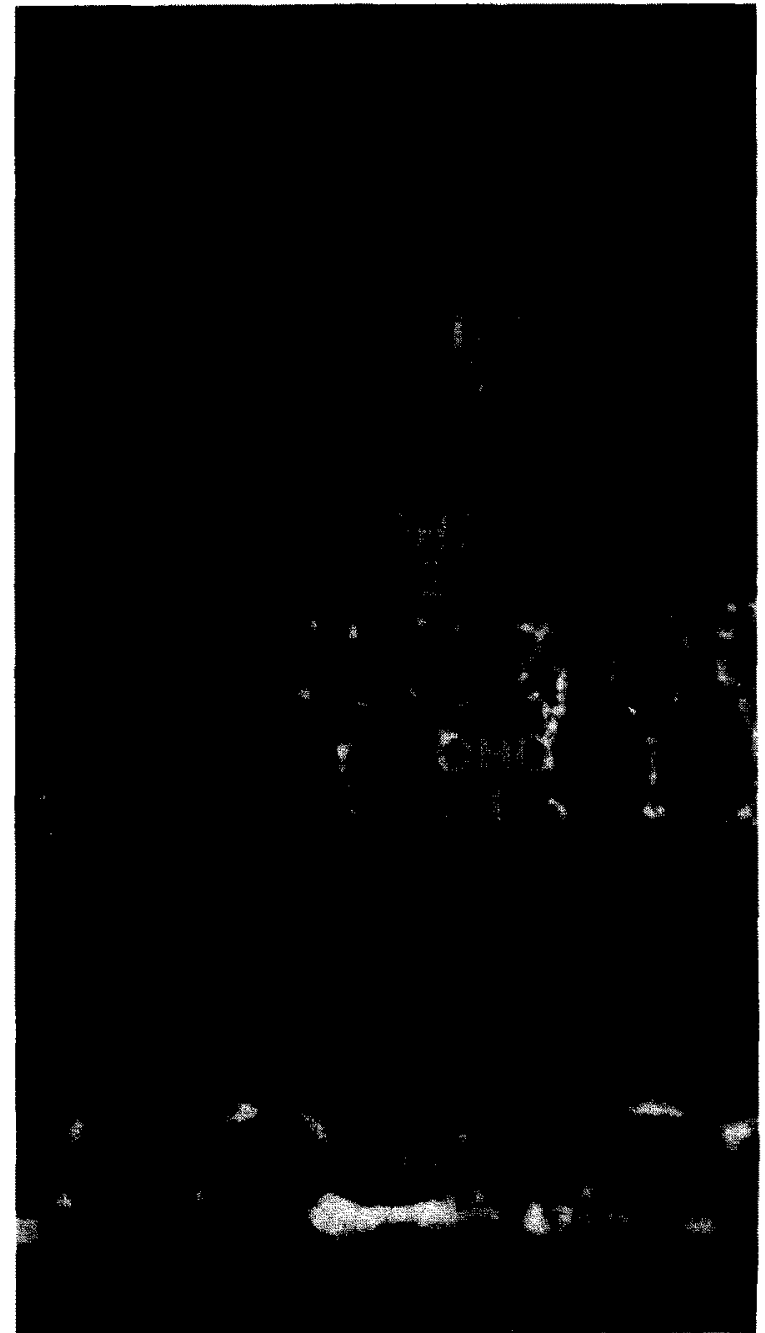

Fig. 2. Immunofluorescence staining of a surface preparation of the organ of Corti by KHRI-3. Punctate staining of the reticular lamina framing the sensory cells (IHC-inner hair cells; OHC 1, 2, 3, outer hair cells, rows 1-3) is prominent. The staining surrounding the first row of outer hair cells gives a distinctive "wine glass" pattern. The labeling is most prominent on the phalangeal processes of the outer pillar cells and Deiters' cells as well as on the apical portions of the inner pillar cells. The relative intensity of the staining in this photo is affected partially by the focal plane. The cells directly in the focal plane i.e. those near the letters OHC 1 appear most intensely stained although all cells in this row and those surrounding the inner hair cells had a similar level of brightness.

whereas sensory cells may contain molecular structures that are highly conserved across different mammalian species. On the other hand, it may reflect the relative amount of antigenic material from these cells in the injected homogenate or in the screening assay. Despite dissections geared towards an enrichment of hair cells, only a few hundred can be retrieved from each cochlea. It is also possible that antigenic structures on the sensory cells may be more easily denatured by the immunization and screening procedure. Thus, other immunization schemes and other cochlear preparations may be necessary to increase the likelihood of developing hair cell specific antibodies. In any case, given the small amounts of antigenic material used for immunization thus far, it is clear that the intrasplenic method is a workable solution for producing antibodies to cochlear tissue antigens.

The patterns of cochlear staining observed with the three antibodies suggests similarities between the KHRI-1 and 2 antibodies. The pattern obtained with KHRI-1 was included within the structures stained by KHRI-2 and was comparable to that seen with diluted KHRI-2, suggesting that both antibodies detect the same antigenic site. The Ig content of KHRI-2 supernatants (52 $\mu \mathrm{g} / \mathrm{ml}$ ) is $10 \mathrm{X}$ higher than those from KHRI-1 $(5 \mu \mathrm{g} / \mathrm{ml})$. Thus, KHRI-1, because of its higher titer may reveal sites of lower density. Neither of these antibodies identified a protein in western blots.

The antibody probe with the most potential for antigen isolation and characterization appears to be KHRI-3 which produces a striking punctate 'wine glass' pattern of staining associated with supporting cells on surface preparations of cochlea. This pattern of immunoreactivity raises the question as to the molecular structure recognized by the antibody and its cellular localization. Staining was found in the apical portion of outer pillar cells (facing the subtectorial space), in the apical portion of Deiters' cell phalangeal processes and medial to inner hair cells, probably in the apex of inner phalangeal cells. Less prominent immunolabeling was present in the inner sulcus and at the borders of Hensen cells. Comparison of immunolabeling with scanning electron microscopic pictures show an interesting correlation with the distribution of microvilli (Ptok et al., 1989). The striking feature of the KHRI 3 antibody is that it stains structures that are completely absent 

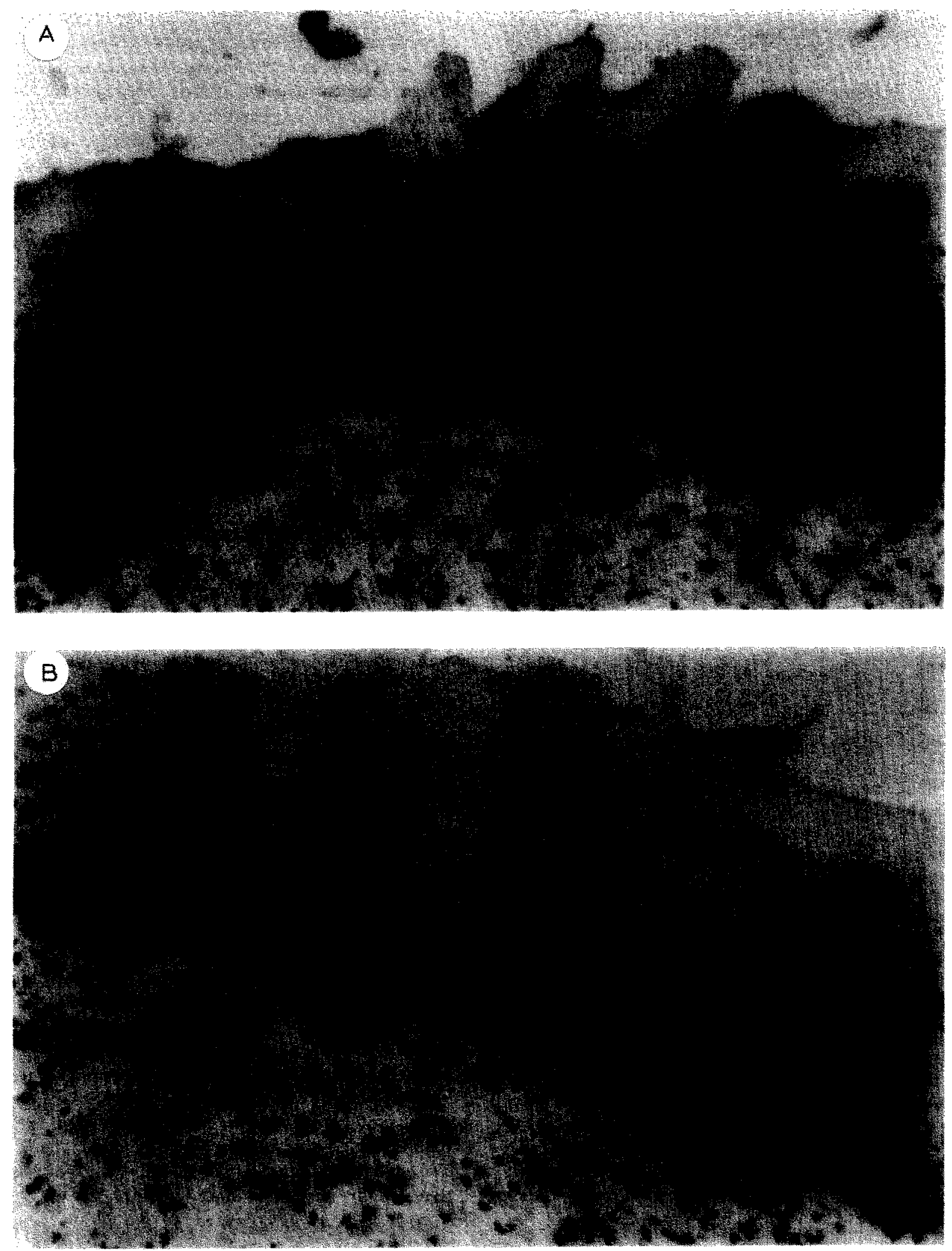

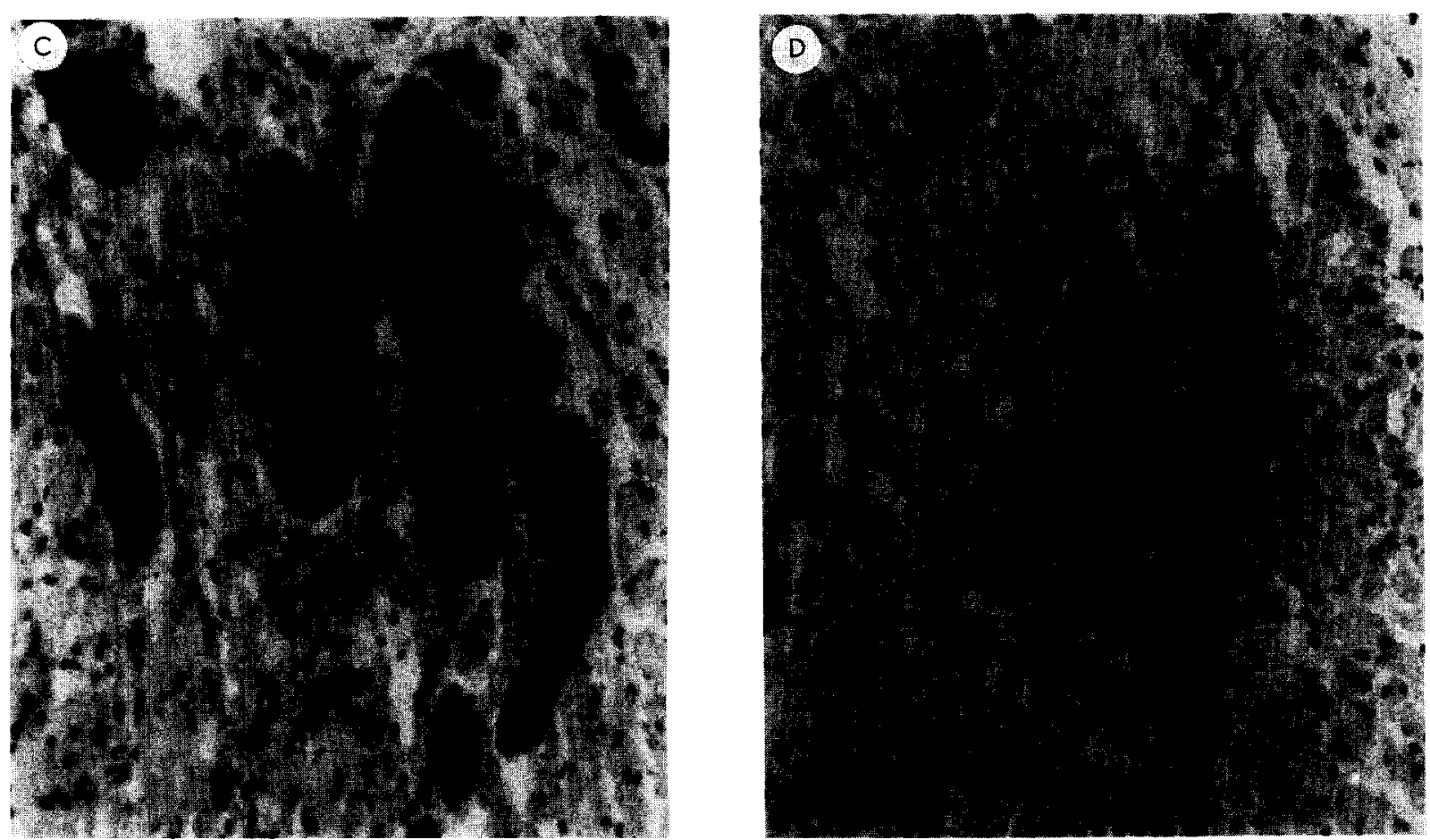

Fig. 3. Immunoperoxidase staining of frozen sections of guinea pig tongue by KHRI-2 and KHRI-3. (A) KHRI-2 stains the basal and suprabasal cells in the epithelium. (B) There is no staining of these cells with Sp2/0 supernatant. (C) KHRI-3 strongly stains peripheral nerve fibers within the muscle layers of submucosal tissues in the tongue. (D) Similar section stained with SP2 $/ 0$ supernatant.

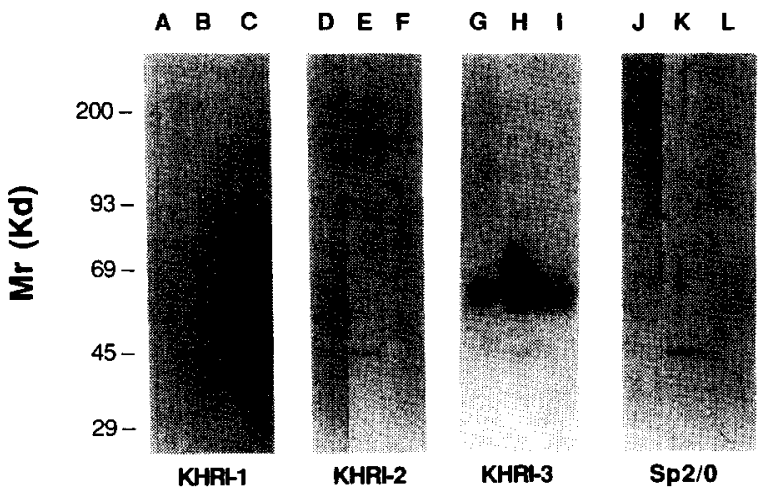

Fig. 4. Western blots of SDS-PAGE-separated tissue extracts immunostained with monoclonal antibodies KHRI-1 (panel 1), KHRI-2 (panel 2), KHRI-3 (panel 3) or with supernatant from the parent myeloma Sp2/O (panel 4). The first lane in each panel contains extract from brain (lanes $A, D, G, J)$. The middle lanes contain cochlea (lanes $B, E, H, K$ ) and the right lanes contain tongue extracts (lanes C, F, I, L). Only KHRI-3 specifically identified proteins on the blots. There were differences in the number of bands and the relative molecular size of the bands detected in cochlea compared to the other tissues. from the hair cells and thus this antibody may be useful for examining the ontogeny of the organ of Corti to distinguish the precursors of the sensory and supporting cell elements.

Although other tissues are stained by KHRI-3, the molecular structure recognized on supporting cells may be unique to the cochlea. The differential effects of fixation on the recognition of the antigen in different tissues indicates that the molecules carrying the epitopes on cochlear supporting cells and peripheral nerve fibers are different. This is also suggested by the fact that Western blotting shows a family of bands $(64,70-75,78 \mathrm{kDa})$ in cochlear tissue extracts in contrast to a $68-70 \mathrm{kDa}$ band in brain and tongue extracts. Alternatively, the small differences in mass could be due to differences in levels of glycosylation of the antigen in the different tissues studied. Resolution of the biochemical character of these molecules is limited by the availability and accessibility of the cells 
that express the antigens. Biosynthetic labeling of antigens in vivo requires large quantities of precursors. Alternatives are to label cochlear cells in vitro or to screen neuronal cultures from peripheral nerves in vitro for expression of the KHRI-3 antigen. The availability of such a culture system would also allow manipulation of the conditions under which the antigen is expressed.

With antibodies specific to supporting elements of the cochlea the role of these cells in inner ear homeostasis and function may be elucidated. This could be accomplished by studying functional deficits following antibody complexing to the antigenic molecule. It is of interest that Harris et al. (1990) have recently reported that antisera raised in guinea pigs immunized with bovine cochlea and antibodies found in the sera of patients with progressive hearing loss both identify bands of approximately $68 \mathrm{kDa}$ on Western blots of cochlear extracts. These findings indicate that autoantibodies to cochlear tissues may be a cause of progressive hearing loss. Thus, if functional deficits are induced in live animals by administration of our monoclonal antibodies then the induced deficit may have an important clinical correlate. Even if there is no effect of the antibodies alone, these reagents can still be examined for induction of functional deficits by conjugating antibodies to toxins (e.g. ricin A chain) to destroy specific cell populations (Ghetie et al., 1988, May et al., 1986, Press et al., 1988). It should also be possible to infer information about the function of the inner ear molecular structures defined by our monoclonal antibodies by isolating the antigen(s), characterizing their biochemical properties, i.e. molecular mass, subunit structure, glycosylation status, amino acid content and sequence, and then comparing these data to the features of known proteins.

In summary, our results demonstrate that it is possible to generate monoclonal antibodies specific for defined cochlear structures that can be used for the localization and identification of unique cochlear proteins. The combined use of such antibodies as molecular markers and as physiological tools should lead to an understanding of the functional properties of the molecular structures they define and the role of the cells that express the structures.

\section{Acknowledgments}

This research was supported by NIH Program Project Grant NS-05785 (DC 00078). Dr. Ptok was supported by a postdoctoral fellowship from the Deutsche Forschungsgemeinschaft. The authors wish to thank Dr. Kathryn Kimmel for performing the fusion that resulted in the production of KHRI-1 and 2. We also appreciate the assistance of Ms. Faith Collins and Ms. Margaret Conlon in typing the manuscript.

\section{References}

Egelman, E. (1981) Problem of light piping in immunofluorescence studies. Nature 294,674 .

Fex, J. and Altschuler, R.A. (1985) Immunohistochemistry of the mammalian cochlea: Results and expectations. In: Auditory Biochemistry, DD Dresher (Ed.), Charles C Thomas, Springfield, pp. 5-30.

Ghetie, V., Ghetie, M.-A. and Vitetta, E.S. (1988) Large scale preparation of immunotoxins constructed with the Fab' fragment of IgG1 murine monoclonal antibodies and chemically deglycosylated ricin A chain. J. Immunol. Methods $112,267-277$.

Harris, J. and Sharp, P. (1990) Inner ear autoantibodies in rapidly progressive sensorineural hearing loss. I aryngoscope (in press).

Hemler, M., Ware, C.F. and Strominger, T.L. (1983) Characterization of a novel differentiation antigen complex recognized by a monoclonal antibody (A1A5) unique activation-specific molecular forms on stimulated T-cells. J. Immunol. 131, 334-340.

Kimmel, K.A. and Carey, T.E. (1986) Altered expression in squamous carcinoma cells of an orientation restricted epithelial antigen detected by monoclonal antibody A9. Cancer Res. 46, 3614-3623.

Köhler, F. and Milstein, C. (1975) Continuous cultures of fused cells secreting antibodies of predefined specificity. Nature 256, 495-497.

Laemmli, U.K. (1970) Clevage of structural proteins during the assembly of the head of bacteriophage T4. Nature 227 , 680-685.

Leibert, M., Ballou, B., Taylor, R., Reiland, J. and Hakala, T. (1985) A method of membrane preparation for immunology. J. Immunol. Methods 85,97-104.

May, R.D., Vitetta, E.S., Moldenhauer, G. and Dörken, B. (1986) Selective killing of normal and neoplastic human B cells with anti-CD19- and anti-CD22-ricin $A$ chain immunotoxins. Cancer Drug Deliv 3, 261-272.

Press, O.W., Martin, P.J., Thorpe, P.E. and Vitetta E.S. (1988) Ricin A-chain containing immunotoxins directed against different epitopes on the CD2 molecule differ in their ability to kill normal and malignant $T$ cells. J. Immunol. 141, 4410-4417.

Ptok, M., Raphael, Y., Carey, T., Schacht, J. and Altschuler, R. 
(1989) Immunocytochemical characterization of changes in the reticular lamina after inner ear trauma. Abst. 26th Inner Ear Biology Workshop: P50, September.

Sonnenberg, A., Modderman, P.W. and Hogervorst, F. (1988) Laminin receptor on platelets is the integrin VLA-6. Nature (London) 336, 487-489.

Spitz, M. (1986) "Single-shot" intrasplenic immunization for the production of monoclonal antibodies. Methods Enzymol. 121, 33-41.
Towbin, H., Stachetin, T. and Gordon, J. (1979) Electrophoretic transfer of protein from polyacrylamide gels to nitrocellulose sheets. Proc. Natl. Acad. Sci. (USA) 76, $4350-4354$.

Zajic, G. and Schacht, J. (1987) Comparison of isolated outer hair cells from five mammalian species. Hear. Res. 26, 249-256. 